\title{
Applying FP_ILM to the retrieval of geometry-dependent effective Lambertian equivalent reflectivity (GE_LER) daily maps from UVN satellite measurements
}

\author{
Diego G. Loyola, Jian Xu, Klaus-Peter Heue, and Walter Zimmer \\ German Aerospace Center (DLR), Remote Sensing Technology Institute, Oberpfaffenhofen, 82234 Weßling, Germany \\ Correspondence: Diego Loyola (diego.loyola@dlr.de)
}

Received: 30 January 2019 - Discussion started: 17 April 2019

Revised: 19 December 2019 - Accepted: 14 January 2020 - Published: 2 March 2020

\begin{abstract}
The retrieval of trace gas, cloud, and aerosol measurements from ultraviolet, visible, and near-infrared (UVN) sensors requires precise information on surface properties that are traditionally obtained from Lambertian equivalent reflectivity (LER) climatologies. The main drawbacks of using LER climatologies for new satellite missions are that (a) climatologies are typically based on previous missions with significantly lower spatial resolutions, (b) they usually do not account fully for satellite-viewing geometry dependencies characterized by bidirectional reflectance distribution function (BRDF) effects, and (c) climatologies may differ considerably from the actual surface conditions especially with snow/ice scenarios.

In this paper we present a novel algorithm for the retrieval of geometry-dependent effective Lambertian equivalent reflectivity (GE_LER) from UVN sensors; the algorithm is based on the full-physics inverse learning machine (FP_ILM) retrieval. Radiances are simulated using a radiative transfer model that takes into account the satellite-viewing geometry, and the inverse problem is solved using machine learning techniques to obtain the GE_LER from satellite measurements.

The GE_LER retrieval is optimized not only for trace gas retrievals employing the DOAS algorithm, but also for the large amount of data from existing and future atmospheric Sentinel satellite missions. The GE_LER can either be deployed directly for the computation of air mass factors (AMFs) using the effective scene approximation or it can be used to create a global gapless geometry-dependent LER (G3_LER) daily map from the GE_LER under clear-sky conditions for the computation of AMFs using the independent pixel approximation.
\end{abstract}

The GE_LER algorithm is applied to measurements of TROPOMI launched in October 2017 on board the EU/ESA Sentinel-5 Precursor (S5P) mission. The TROPOMI GE_LER/G3_LER results are compared with climatological OMI and GOME-2 LER datasets and the advantages of using GE_LER/G3_LER are demonstrated for the retrieval of total ozone from TROPOMI.

\section{Introduction}

The lack of knowledge of the magnitude of surface reflectance and the neglect of surface anisotropic effects are the two major error sources in the retrieval of trace gas, cloud, and aerosol information from ultraviolet, visible, and near-infrared (UVN) satellite measurements (Vasilkov et al., 2018; Lorente et al., 2018; Lin et al., 2014; Seidel et al., 2012; Zhou et al., 2010). Surface reflectance has a stronger influence on the retrievals of boundary layer trace gases and aerosols than is the case for mid- and upper-tropospheric trace gas and cloud retrievals. For example, errors of 0.02 in the surface reflectivity may induce errors of $10 \%-20 \%$ in retrieved $\mathrm{SO}_{2}$ column amount (Lee et al., 2009), and seasonal snow cover can change the retrieved $\mathrm{NO}_{2}$ column by $20 \%$ $50 \%$ (O'Byrne et al., 2010) and the retrieved $\mathrm{O}_{3}$ column by $5 \%-15 \%$ (Lerot et al., 2014).

The concept of Lambertian equivalent reflectivity (LER) was first introduced for BUV (backscatter ultraviolet) total ozone retrievals (Mateer et al., 1971) and it was extended to retrievals of tropospheric ozone, $\mathrm{NO}_{2}, \mathrm{SO}_{2}$, and other pollutants under partly cloudy conditions using the independent pixel approximation (Ahmad et al., 2004). Traditionally, sur- 
face properties are obtained from LER climatologies, and in the case of new missions such as TROPOMI launched in October 2017 on board the EU/ESA Sentinel-5 Precursor (S5P) mission, climatologies used at mission start are based on LER data from previous missions such as TOMS (Herman and Celarier, 1997), GOME (Koelemeijer et al., 2003), OMI (Kleipool et al., 2008), SCIAMACHY (Tilstra et al., 2017), and GOME-2 (Pflug et al., 2008).

The unprecedented spatial resolution of TROPOMI $(3.5 \times$ $5.5 \mathrm{~km}^{2}$ currently and $3.5 \times 7 \mathrm{~km}^{2}$ for data from before $6 \mathrm{Au}-$ gust 2019) has clearly shown the disadvantages of using LER climatologies based on previous missions with significantly lower spatial resolution. Indeed, initial studies of the TROPOMI trace gas retrieved products based on such LER climatologies have exhibited flawed patterns related to the coarser resolution of the OMI LER climatology. A LER climatology based on TROPOMI measurements could solve this particular problem, but creating a new TROPOMI LER climatology will probably require at least 2 years of data. Furthermore, there are two common problems with typical LER climatologies: (a) the actual surface conditions of a satellite measurement may differ considerably from climatological values, as for example for snow/ice scenarios, and (b) the effect of surface reflectance anisotropy is usually not properly covered by the climatology.

The retrieval of Lambertian effective scene albedo has been used in total ozone algorithms from nadir and limb satellite sensors; see for example Bhartia et al. (1996) and McPeters et al. (2015). The WFDOAS (Coldewey-Egbers et al., 2005) algorithm retrieves the effective LER at $377 \mathrm{~nm}$, while the GODFIT (Lerot et al., 2010) and SAGE III (Rault and Taha, 2007) approaches both retrieve simultaneously the effective LER and other parameters along with total ozone.

Another approach used for $\mathrm{NO}_{2}$ and cloud retrievals involved the computation of LER from bidirectional reflectance distribution function (BRDF) data obtained from other satellite sensors with higher spatial resolution. In a recent work (Vasilkov et al., 2017), the BRDF data from MODIS are first resampled to the lower resolution of the OMI instrument, and then a geometry-dependent LER is computed using radiative transfer model simulations. Unfortunately MODIS BRDF data are available only from visible (VIS) wavelengths, and rescaling the VIS BRDF (or LER) to UV is not straightforward. Furthermore, the radiative transfer (RT) model assumptions needed for computing MODIS BRDFs may not be fully compatible with RT model assumptions required for UV-based trace gas retrievals.

In this paper we present a novel algorithm to be used not only for the retrieval of geometry-dependent effective Lambertian equivalent reflectivity (GE_LER) from UVN measurements, but also for the creation of a global gapless geometry-dependent LER (G3_LER) daily map based on GE_LER data obtained for clear-sky conditions. The retrieved GE_LER and G3_LER should accurately represent the current surface conditions, while mitigating the prob- lems of using LER climatologies and accounting for surface anisotropy effects in cloud, aerosol and trace gas retrievals, in a similar manner as does the effective LER (ColdeweyEgbers et al., 2005) and the geometry-dependent LER (Qin et al., 2019). However, in contrast to these approaches, the GE_LER retrieval is performed in precisely the same fitting windows used for the trace gas, cloud, and aerosol retrievals themselves; furthermore our algorithm does not require external data sources such as BRDFs (land surfaces) or Chlorophyll and wind parameters (water surfaces).

First we describe in Sect. 2 the full-physics inverse learning machine (FP_ILM) technique used for the retrieval of GE_LER from UVN measurements, and we demonstrate how it is optimized for DOAS trace gas retrievals. Section 3 discusses the creation of global gapless geometry-dependent LER (G3_LER) daily maps using the retrieved GE_LER for clear-sky conditions. In Sect. 4 we apply the GE_LER algorithms to S5P measurements, first comparing TROPOMI G3_LER results with climatological OMI and GOME-2 LER data, and secondly we demonstrate the advantages of using GE_LER/G3_LER for the retrieval of total ozone from TROPOMI. In Sect. 5 we discuss future work.

\section{The FP_ILM algorithm for the GE_LER retrieval}

Trace gas, cloud, and aerosol retrievals from UVN measurements rely on complex radiative transfer model (RTM) simulations. RTM calculations are computationally expensive and therefore not well suited for processing massive amounts of data from the new generation of atmospheric composition Sentinel missions. A classical approach for speeding up RTM performance is to use look-up tables (LUTs). The main drawbacks of LUTs with high dimensionality (common in atmospheric composition retrievals) are that the memory requirements increase exponentially with the number of input dimensions, the interpolation/extrapolation in this multidimensional space is computationally expensive, and interpolation/extrapolation errors can be significant. To avoid these LUT issues, during the last 2 decades, the DLR team has developed machine learning techniques for the optimal generation of RTM samples (Loyola et al., 2016) and the accurate parameterization of RTM simulations using artificial neural networks (NNs). These algorithms are being used for the operational processing of GOME-2 (Loyola et al., 2010) and now TROPOMI (Loyola et al., 2018) data.

Machine learning can be used not only for forward problems (such as the parameterization of RTM simulations), but also for solving inverse problems; see for example (Loyola et al., 2006). Recently we have developed an approach called the "full-physics inverse learning machine" (FP_ILM) technique; this has been applied successfully for retrieving ozone profile shapes from GOME-2 (Xu et al., 2017) and retrieving $\mathrm{SO}_{2}$ layer height from GOME-2 (Efremenko et al., 2017) and TROPOMI (Hedelt et al., 2019). 


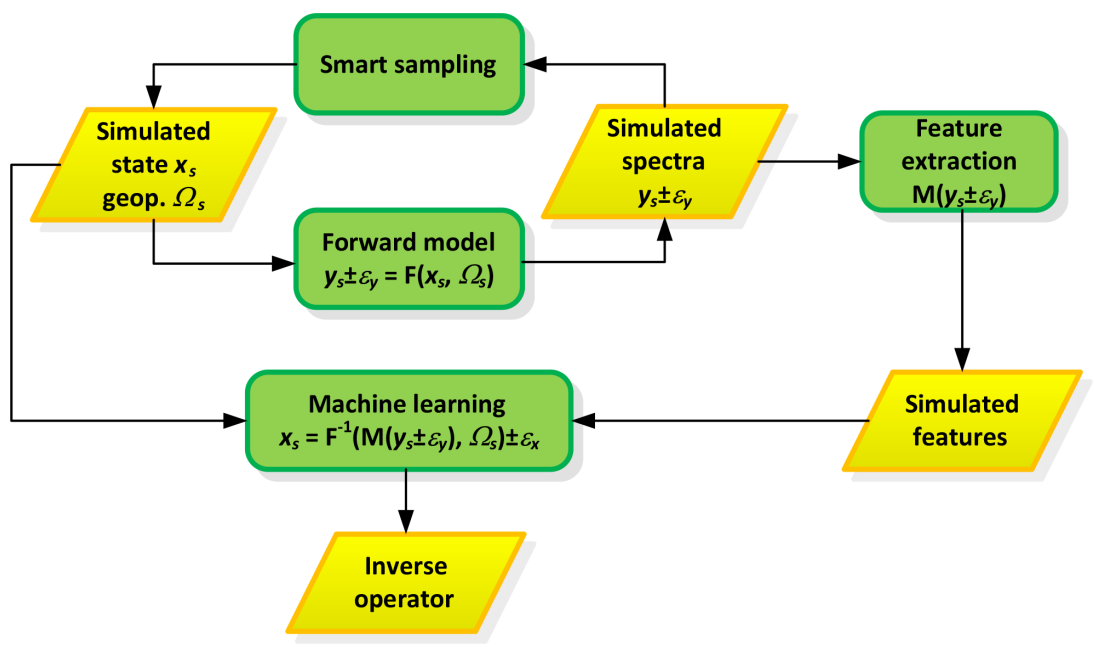

Figure 1. Data flow diagram for the FP_ILM training phase. The smart sampling technique creates simulated state vector $\boldsymbol{x}_{\mathrm{s}}$ and geophysical conditions $\Omega_{\mathrm{s}}$ that are used as input for the forward model for the calculation of simulated spectra, with their expected errors $\boldsymbol{y}_{\mathrm{s}}+e_{y}$. Machine learning techniques are deployed for computing the inverse operator, which is trained using the features extracted from simulated spectra $M\left(y_{\mathrm{s}}\right)$ and geophysical conditions $\Omega_{\mathrm{s}}$ as input, and the state vector and the errors $\boldsymbol{x}_{\mathrm{s}}+e_{x}$ as output.

Figure 1 presents a flow diagram of the different steps of the FP_ILM algorithm and the following subsections describe in more detail how FP_ILM is tailored for the retrieval of GE_LER.

\subsection{Forward model}

The forward model segment has two components: first a radiative transfer model (RTM) that computes spectral intensity as a function of the solar and viewing geometry, atmospheric components, and Lambertian surface properties; and second a sensor model that transforms the RTM intensities to simulated spectra using sensor information such as the instrument spectral response function and signal-to-noise ratio.

The forward model $F$ will simulate spectral radiances $R_{\text {sim }}$ for a given wavelength $\lambda$ according to

$R_{\text {sim }}(\lambda) \pm \varepsilon_{R}=F\left(\lambda, \Theta, \Omega, A_{\mathrm{e}}, Z_{\mathrm{e}}\right)$,

where $\varepsilon_{R}$ denotes the expected instrument error, $\Theta$ is the light path geometry (solar and satellite zenith and azimuth angles), $\Omega$ are the atmospheric composition components, and surface properties are denoted by $A_{\mathrm{e}}$ for the geometry-dependent effective Lambertian equivalent reflectivity (GE_LER) and $Z_{\mathrm{e}}$ for the effective surface height.

\subsection{Smart sampling}

Traditionally, training data are created at uniformly distributed fixed intervals for each input variable; as a consequence, the training samples are grouped around the node points and poor coverage of the multidimensional input space is the result. Deterministic sampling methods provide a more uniform distribution of the training data covering the entire space of each input variable.
A key element of FP_ILM is the creation of a training data set that covers extensively the multidimensional space of the forward problem and at the same time minimizes the computationally expensive calls to the radiative transfer model. We use the smart sampling techniques (Loyola et al., 2016) for creating a dataset of samples $\left\{\Theta, \Omega, A_{\mathrm{e}}, Z_{\mathrm{e}}\right\}$ that fully represents the expected viewing and geophysical conditions of the problem at hand. For this work we select a Halton sequence that uses prime numbers for creating sample points in each input dimension and an RTM that computes the corresponding simulated radiances.

As indicated in Fig. 1, the smart sampling and forward module calls are iterated in a loop until the multidimensional integral of the output samples dataset $\left\{R_{\text {sim }}(\lambda) \pm \varepsilon_{R}\right\}$ converges. This technique allows us to determine the minimum number of samples needed to properly cover the output space; see Loyola et al. (2016) for more details.

\subsection{Feature extraction}

Retrieval of trace gas, cloud, and aerosol concentrations from UVN sensors requires spectrometers with sufficiently detailed spectral resolution to resolve absorbing features in the electromagnetic spectrum. The fitting window used for retrieval of a trace gas usually requires hyperspectral radiances for high-dimensional space (tens to hundreds of wavelengths). Machine learning techniques perform best with low-dimensional datasets.

Feature extraction is a mapping function that transforms a dataset from a high- to a low-dimensional space by the removal of redundant information and noise. In previous FP_ILM applications (Loyola et al., 2006; Xu et al., 2017) we used principal component analysis for feature extraction. 


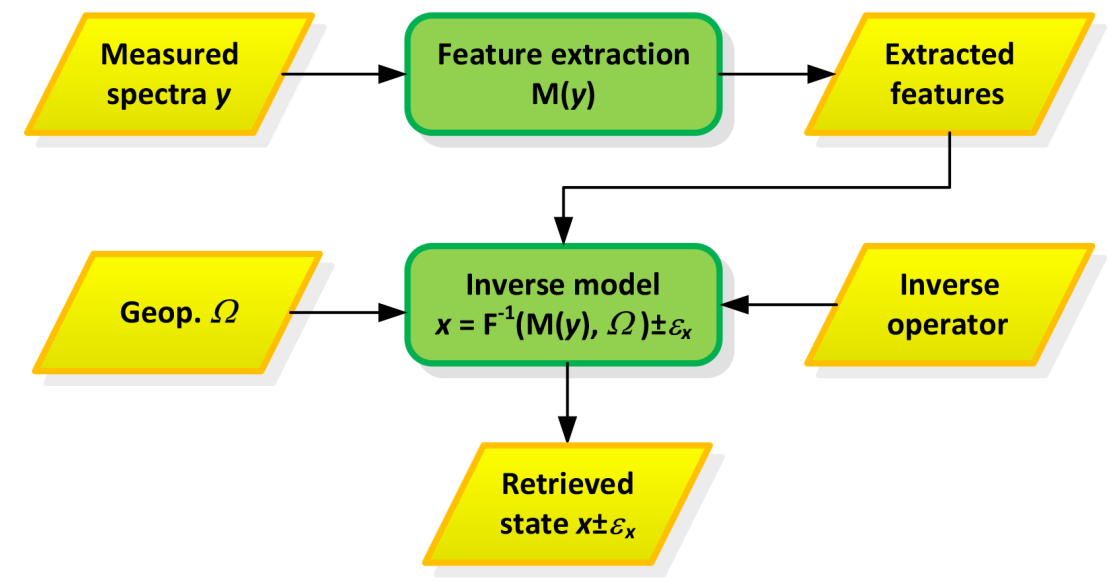

Figure 2. Data flow diagram for the FP_ILM retrieval phase. The inverse operator computed during the FP_ILM training phase solves the inverse problem and retrieves the state vector $\boldsymbol{x}$, taking as input the features $M(y)$ extracted from the measured spectra $\boldsymbol{y}$ and geophysical conditions $\Omega$.

However for the GE_LER retrieval we take advantage of the DOAS fitting model:

$R_{\mathrm{sim}}(\lambda)=-\sum_{g} N_{\mathrm{s}, g}(\Theta) \cdot \sigma_{g}(\lambda)-p(\lambda)$,

where $N_{\mathrm{s}, g}(\Theta)$ is the effective slant column density of gas $g$ for light path geometry $\Theta, \sigma_{g}(\lambda)$ the associated trace gas absorption cross-section at wavelength $\lambda$, and $p(\lambda)$ an external closure polynomial.

The feature extraction step comprises an application of the DOAS fit to the simulated radiances. Combining (1) and (2) for a given fitting window $\Lambda$ we obtain the following approximation with simulated datasets that represent the forward problem:

$\left\{N_{\mathrm{s}, g}(\Theta), p(\Lambda)\right\} \cong\left\{F\left(\Theta, A_{\mathrm{e}}(\Lambda), Z_{\mathrm{e}}\right)\right\}$,

where $A_{\mathrm{e}}(\Lambda)$ is the wavelength-independent GE_LER for the particular DOAS fitting window.

\subsection{Machine learning}

Machine learning approximates a function that is represented by input/output datasets by means of linear or non-linear regression algorithms. In this paper we use artificial NNs to learn the non-linear inverse problem by reorganizing the datasets from (3) to represent the inverse problem:

$$
\left\{A_{\mathrm{e}}(\Lambda)\right\} \cong\left\{F_{\mathrm{NN}}^{-1}\left(p(\Lambda), N_{\mathrm{s}, g}, \Theta, Z_{\mathrm{e}}\right)\right\} .
$$

In other words, a neural network will solve the inverse problem and retrieve the GE_LER as a function of the DOAS closure polynomial, the DOAS-fitted effective slant column density, the viewing geometry, and the effective surface height. The inverse operator itself is the collection of the weights and biases of the neural network approximating $F_{\mathrm{NN}}^{-1}$.

\subsection{GE_LER retrieval}

Obtaining the inverse operator is very time consuming mainly due to the relatively large amount of RTM simulations needed to properly characterize the forward problem. Finding a NN topology that learns the inverse function with minimum error is also computationally intensive. However, all these steps are carried out offline and need to be done only once for a given sensor and trace gas fitting window.

Figure 2 shows the flow diagram for applying the FP_ILM to satellite measurements. There is no additional computation needed for the feature extraction part, as we are using results from the DOAS fitting; also, application of the NN to retrieve GE_LER is very fast as it only involves simple matrix multiplications.

The exceptionally fast retrieval using the FP_ILM is a crucial advantage for the operational near-real-time processing of big data from current and future atmospheric composition Sentinel missions.

\section{Global gapless geometry-dependent (G3) LER daily map}

Conversion of DOAS effective slant column amounts to geometry-independent total column requires the calculation of air mass factors (AMFs) calculated using either the effective scene approximation (Mateer et al., 1971; ColdeweyEgbers et al., 2005) or the independent pixel approximation (e.g. Loyola et al., 2011). The retrieved GE_LER can be used directly for AMF computation based on the effective scene approximation; clear-sky LER is needed for AMFs calculated with the independent pixel approximation.

A global gapless geometry-dependent LER (G3_LER) daily map can be easily created from GE_LER values retrieved under clear-sky conditions. In the case of S5P, a clear- 


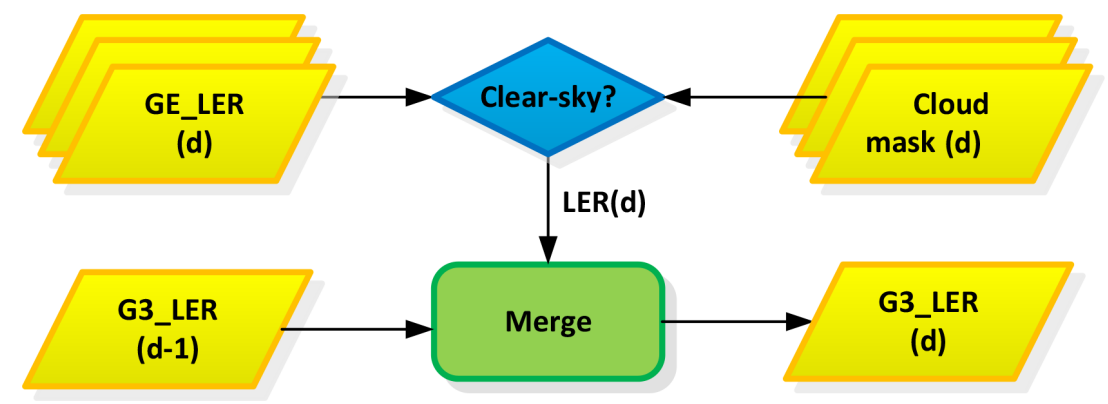

Figure 3. Data flow diagram for the creation of the global gapless geometry-dependent LER (G3_LER) map for day, d, obtained by merging the clear-sky LER data from the same day with the G3_LER map from the previous day.

sky situation is established not only with the operational cloud properties retrieved from TROPOMI (Loyola et al., 2018) but also with the VIIRS/SNPP (Visible Infrared Imaging Radiometer Suite sensor, on board the Suomi National Polar-orbiting Partnership satellite) cloud mask regridded to the TROPOMI spatial resolution (Siddans, 2016). Note that S5P and SNPP fly in loose formation, with the S5P orbit trailing 3 to 5 min behind SNPP.

The G3_LER map for a given day is created by merging the clear-sky GE_LER data from the same day with the G3_LER map based on the GE_LER data from previous days; see Fig. 3. The spatial resolution of the G3_LER maps for TROPOMI is $0.1^{\circ}$ latitude and $0.1^{\circ}$ longitude, and global maps can in general be derived by combining data from a single month. Two to three months of data are needed only for regions with persistent cloud cover such as the Intertropical Convergence Zone (ITCZ).

It is important to note that the GE_LER determination incorporates bidirectional reflectance distribution function (BRDF) effects, since it is based on radiative transfer model simulations using the actual viewing geometry. When combining GE_LER data, their BRDF dependencies $\rho(\Lambda, \psi, \theta)$ as a function of the wavelength in the fitting window $\Lambda$, the viewing zenith angle $\theta$, and the surface type $\psi$ must be considered. In contrast, solar zenith angle dependencies can be ignored when combining GE_LER data from sunsynchronous satellites over the same location because the angle of sunlight at the Earth's surface is constantly maintained. Likewise, relative azimuth angle dependencies are negligible in the UV. The $\rho(\Lambda, \psi, \theta)$ dependencies can be obtained separately for different fitting windows $\Lambda$ (in the UV, VIS, and NIR spectral region), for different surface types $\psi$ (e.g. land, water, and snow/ice), and various time periods (e.g. monthly); any dependency on viewing zenith angle can be characterized by fitting a polynomial (or exponential) function over clear-sky LERs sorted as a function of $\theta$.

The G3_LER daily map comprises the normalized LER, i.e. the GE_LER retrieved under clear-sky conditions divided by the fitted BRDF dependency, as well as the multiplicative factors $\rho(\theta)$ needed to compute the geometry-dependent
Table 1. Ranges of input parameters appropriate for radiance simulations in the total ozone fitting window; ozone profiles are classified as a function of the total column. Smart sampling is employed to generate node points optimally covering all input dimensions, and more than $2 \times 10^{5}$ synthetic UV spectra are generated.

\begin{tabular}{lrr}
\hline Parameter & Minimum & Maximum \\
\hline Ozone profile & $125 \mathrm{DU}$ & $575 \mathrm{DU}$ \\
Solar zenith angle & $0^{\circ}$ & $90^{\circ}$ \\
Viewing zenith angle & $0^{\circ}$ & $70^{\circ}$ \\
Relative azimuth angle & $0^{\circ}$ & $180^{\circ}$ \\
Surface albedo & 0 & 1 \\
Surface pressure & $125 \mathrm{hPa}$ & $1013 \mathrm{hPa}$ \\
\hline
\end{tabular}

LER as a function of the actual satellite-viewing zenith angle $\theta$.

It is necessary to aggregate normalized LER retrievals over several days (between 1 to 4 weeks depending on cloudiness) in order to obtain a global gapless map. In contrast to LER climatologies, the G3_LER map represents actual surface properties as it is updated on a daily basis. The only exceptions are cases of sudden snow fall combined with significant cloudiness.

\section{GE_LER and G3_LER from TROPOMI/S5P 325-335 nm}

In this section, we apply the GE_LER and G3_LER algorithms described in the previous sections to measurements of TROPOMI/S5P in the total ozone wavelength region. The S5P operational near-real-time total ozone products (Loyola et al., 2020) are based on the DOAS algorithm with a fitting window of 325-335 nm. First we discuss aspects of the training process.

\subsection{GE_LER training}

The training dataset is based on spectra simulated by the Vector LInearized Discrete Ordinate Radiative Transfer (VLIDORT) model (Spurr, 2016). The RTM inputs are ozone 

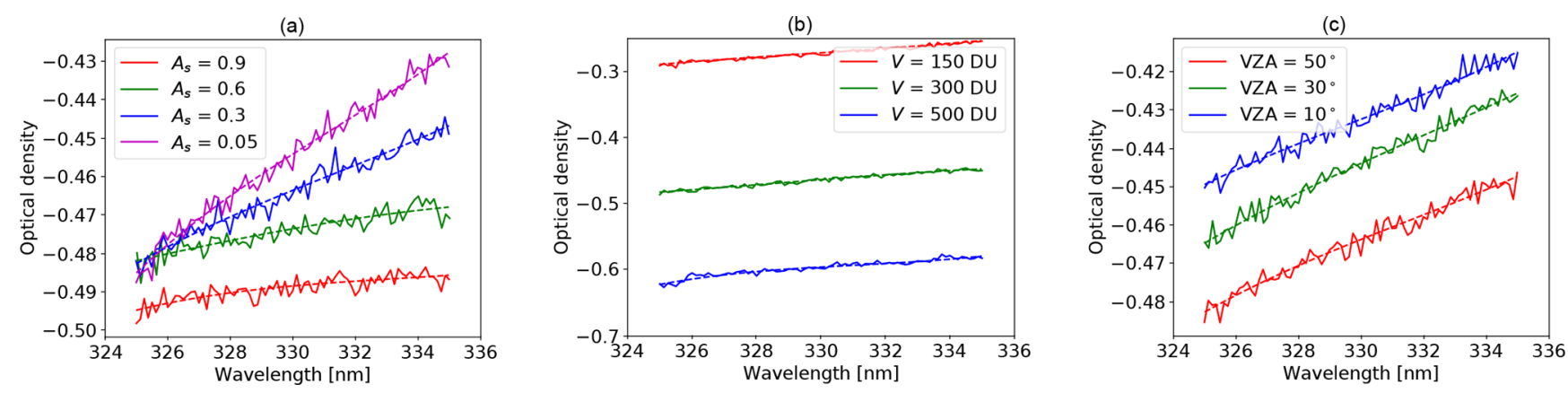

Figure 4. Optical densities of the DOAS polynomial as a function of wavelength, with respect to (a) surface albedo, (b) total ozone, and (c) viewing zenith angle. The dotted lines represent the DOAS-fitted polynomial.

concentration profiles, Lambertian surface albedo, surface height, and the solar and viewing angles. The smart-sampling technique (Loyola et al., 2016) was used to create more than $2 \times 10^{5}$ synthetic UV spectra for the ozone profile, viewing geometry and surface parameters in the ranges listed in Table 1. We use the Bodeker et al. (2013) ozone profile climatology for representing the stratospheric ozone in conjunction with the McPeters/Labow (Labow et al., 2015) climatology for lower tropospheric ozone.

Synthetic TROPOMI/S5P measurements are created by convolving these RTM radiances with the instrument slit function and adding Gaussian instrument noise with a signalto-noise ratio of 300, representative of TROPOMI band 3; see Kleipool et al. (2018).

The DOAS fitting is applied to these simulated S5P radiances using the same DOAS settings as in the operational S5P retrieval including a cubic external-closure polynomial, resulting in a dataset of ozone slant columns and associated polynomial coefficients.

Figure 4 shows the optical densities of the DOAS polynomial $p(\lambda)$ in Eq. (1) for three scenarios. In panel (a) these are given as functions of four typical values of surface albedo of $0.05,0.3,0.6$, and 0.9 , which correspond to water, land, melted snow/ice-cover and fresh snow/ice-covered regions. The largest absolute value of the optical density corresponds to the highest surface albedo; optical densities for the four albedos do not differ significantly at lower wavelengths, while the differences are more significant at the higher wavelengths. In panel (b) optical densities of the DOAS polynomial are shown with respect to three total ozone columns of 150,300 , and $500 \mathrm{DU}$; the absolute value of the optical density increases when the total ozone column increases. Finally, in panel (c) densities are plotted for three viewing zenith angles: 50,30 , and $10^{\circ}$; the absolute value of the optical density increases with decreasing viewing zenith angle. For all cases, optical density increases with wavelength.

The simulation results from Eq. (3) are reorganized by grouping the DOAS polynomial coefficients, ozone slant column, the viewing geometries, and surface heights as inputs to the neural network. A feedforward neural network (the neurons are grouped in layers) is trained to learn the inverse function (retrieval of surface albedo) using $70 \%$ of the simulations for training, $15 \%$ for testing and $15 \%$ for validation. Different NN topologies were tested using one, two, and three hidden layers; the best results are obtained using a NN with a topology of 9-20-8-2-1, which is 9 neurons in the input layer, three hidden layers with the given number of neurons, and 1 neuron in the output layer.

In Fig. 5, we depict the GE_LER retrieval errors as a function of the different input parameters calculated using the validation dataset (i.e. part of the dataset not used for NN training); the $x$ axes are divided into bins, and the mean and standard deviation (red bars) are calculated for each bin. Differences between the true and retrieved GE_LER are very small with a mean and standard deviation of only $0.0016 \pm 0.0018$. These results demonstrate that the $\mathrm{NN}$ represents the inverse function in a very accurate manner.

The Ring effect (filling-in of Fraunhofer and telluric spectral signatures through inelastic rotational-Raman scattering by air molecules) is a significant spectral interference in DOAS total ozone fitting in the $325-335 \mathrm{~nm}$ window. We tested its impact on the GE_LER training by adding fillingin corrections obtained with the LIDORT-RRS model (Spurr et al., 2008) to the VLIDORT simulations. We found that the Ring-effect impact on GE_LER retrieval in the ozone fitting window is not significant. Indeed, the mean difference in GE_LER retrievals with and without the inclusion of LIDORT-RRS corrections is in the range of $5 \times 10^{-5}$ for $\mathrm{SZA}<75^{\circ}$ and $3.5 \times 10^{-4}$ for larger SZA.

The BRDF effects on the ozone fitting window are well modelled using the GE_LER approximation; the difference in the total ozone retrieved using VLIDORT with and without the BRDF supplement is in the order of $0.5 \mathrm{DU}$ or $0.2 \%$.

\subsection{GE_LER retrieval}

The neural network trained with the inverse function is applied to TROPOMI/S5P measurements. The inputs are the DOAS-fitted polynomial coefficients and ozone slant column, the solar and viewing zenith angles, the relative az- 

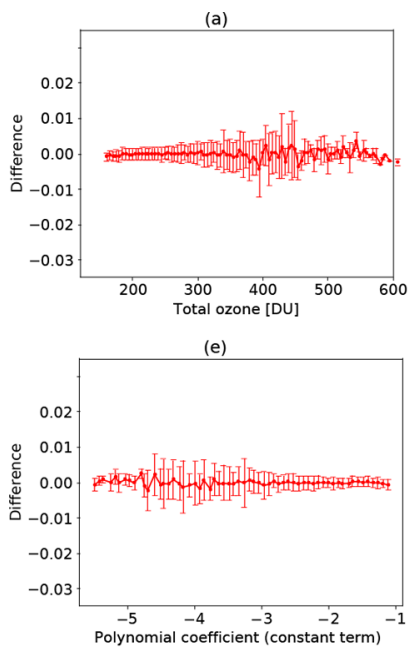
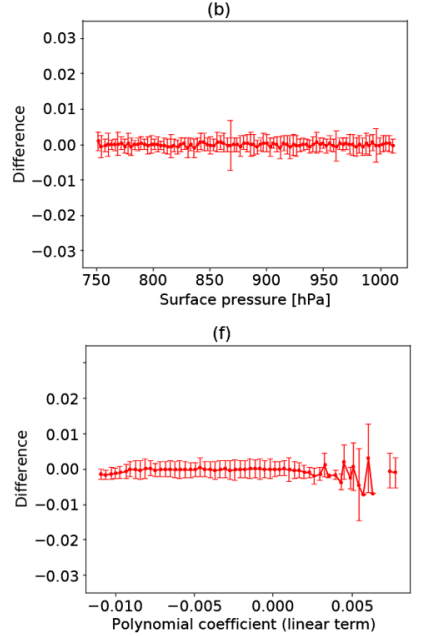
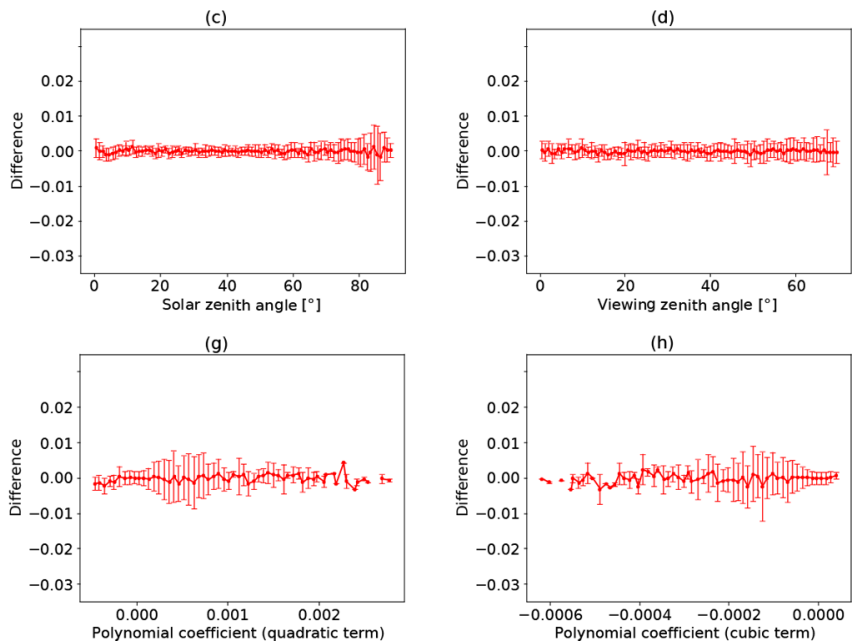

Figure 5. GE_LER retrieval error as a function of (a) total ozone, (b) surface pressure, (c) solar zenith angle, (d) viewing zenith angle, and $(\mathbf{e}$ to $\mathbf{h})$ the four DOAS polynomial fitting coefficients.

imuth angle, and the effective surface height $Z_{\mathrm{e}}$ computed in the independent pixel approximation as

$Z_{\mathrm{e}}=\left(1-f_{\mathrm{c}}\right) Z_{\mathrm{s}}+f_{\mathrm{c}} Z_{\mathrm{c}}$,

where $f_{\mathrm{c}}$ is the cloud fraction, $Z_{\mathrm{s}}$ the surface height, and $Z_{\mathrm{c}}$ the cloud height. The S5P cloud properties are obtained from the operational TROPOMI cloud products using the OCRA and ROCINN algorithms (Lutz et al., 2016; Loyola et al., 2018).

It is known that version 1 of the TROPOMI Level 1 product has small deficiencies in the UV band (Rozemeijer and Kleipool, 2019); therefore a "soft" correction based on comparisons with OMPS radiances is applied to the S5P radiances. It is expected that these issues will be solved for version 2 of the TROPOMI Level 1 product, obviating the need for this soft correction.

TROPOMI/S5P GE_LER results for the total ozone fitting window $(325-335 \mathrm{~nm})$ for 10 April 2018 are shown in Fig. 6. As expected the GE_LER field shows the same patterns as the cloud field for that day. For clear-sky conditions $\left(f_{\mathrm{c}} \leq 0.05\right)$ the GE_LER represents the hemispherical surface albedo, while for cloudy scenarios $\left(f_{\mathrm{c}} \geq 0.95\right)$ GE_LER represents the cloud albedo. Figure 7 shows histograms of the differences between the TROPOMI clear-sky GE_LER and the OMI LER climatology (Kleipool et al., 2008), and also the differences between the cloudy TROPOMI GE_LER and the cloud albedo from the operational cloud product retrieved with ROCINN_CRB (Loyola et al., 2018). The second mode around 0.5 in the histogram indicates snow- or ice-cover scenarios in TROPOMI data that are poorly represented with the OMI LER climatology. The comparison between S5P GE_LER and the GOME-2 and OMI climatologies is discussed in more detail in Sect. 4.4.

Mean differences for the clear-sky and cloudy cases as a function of the surface type are summarized in Table 2 and
Table 2. Summary of the comparison between TROPOMI GE_LER clear-sky and OMI LER (first three rows) and between TROPOMI GE_LER cloudy and ROCINN_CRB cloud albedo (rows 4-6). There are more than 4.5 million clear-sky and 1.4 million cloudy cases out of approximately 15 million S5P measurements from 10 April 2018.

\begin{tabular}{lrrr}
\hline & Number & Mean & SD \\
\hline Clear-sky land & 866907 & 0.0014 & 0.0624 \\
Clear-sky water & 1837686 & -0.0144 & 0.0762 \\
Clear-sky snow/ice & 1852222 & -0.0048 & 0.2573 \\
Cloudy land & 254645 & 0.0834 & 0.1865 \\
Cloudy water & 1084985 & 0.0487 & 0.1464 \\
Cloudy snow/ice & 127636 & -0.0343 & 0.5432 \\
\hline
\end{tabular}

Fig. 7, with relatively larger offsets and spreads mainly due to the difference in spectral regions between GE_LER retrieved in the UV (325-335 nm) and the cloud properties retrieved with ROCINN_CRB from the $\mathrm{O}_{2}$ A-band in the NIR (758$771 \mathrm{~nm})$.

\subsection{G3_LER daily map}

The TROPOMI G3_LER map for a given day is created by regridding (at a resolution of $0.1^{\circ} \times 0.1^{\circ}$ ) the clear-sky LER data from the same day with the G3_LER map based on LER data from previous days. The LERs are obtained from the S5P GE_LER retrievals under clear-sky conditions. In this version of the TROPOMI G3_LER map we use the S5P OCRA and the VIIRS/SNPP (flying in constellation with $\mathrm{S} 5 \mathrm{P})$ cloud fractions $f_{\mathrm{c}}$ for identifying clear-sky measurements $\left(f_{\mathrm{c}} \leq 0.05\right.$ is the criterion here). In the future we plan to additionally use the S5P absorbing aerosol index product for an even more stringent cloud/aerosol screening. 
(a) GE LER from 2018-04-10

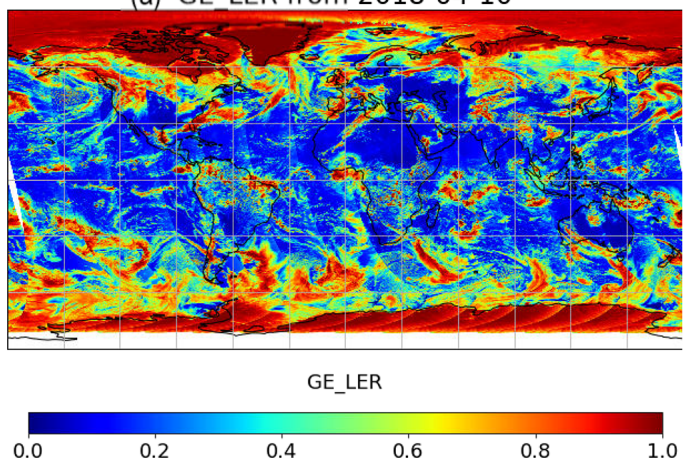

(b) Cloud fraction from 2018-04-10

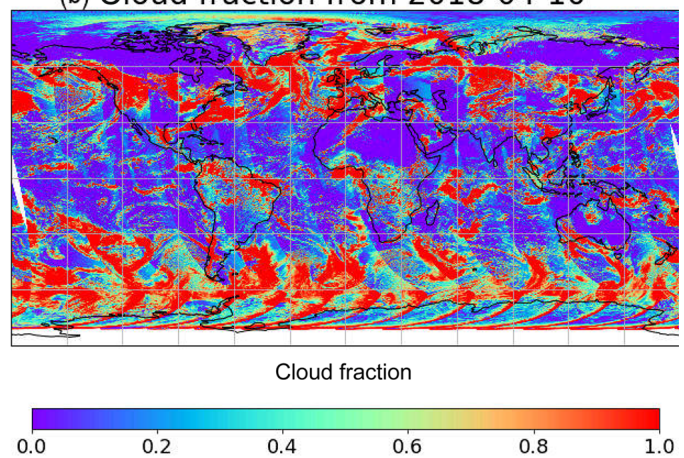

Figure 6. (a) GE_LER in the total ozone fitting window $(325-335 \mathrm{~nm})$ retrieved from TROPOMI/S5P data on 10 April 2018 and (b) the corresponding cloud fraction for this day.
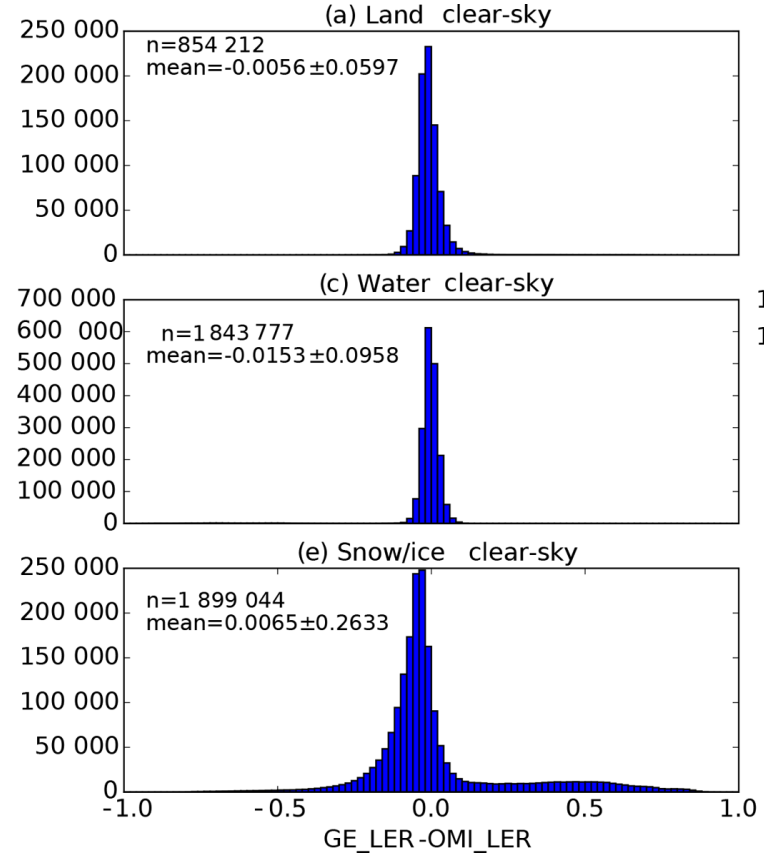

(b) Land cloudy

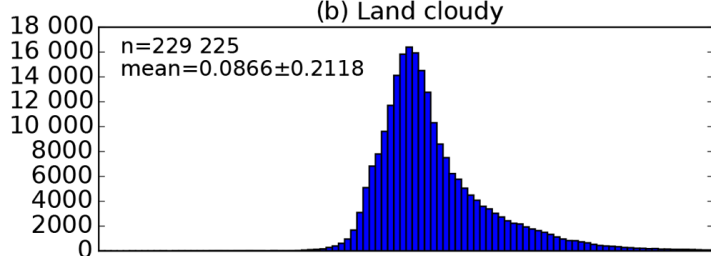

(d) Water cloudy
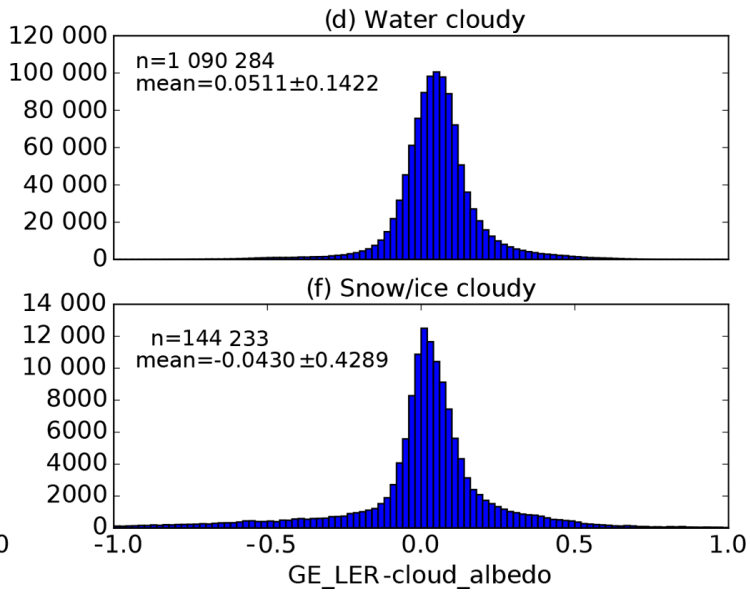

Figure 7. Histograms of the differences $(\mathbf{a}, \mathbf{c}, \mathbf{e})$ between clear-sky TROPOMI GE_LER and OMI LER climatology and (b, d, f) between the cloudy TROPOMI GE_LER and the ROCINN_CRB cloud albedo from the operational S5P cloud product. The comparisons are performed separately according to surface types (land, water, and snow/ice), with S5P data from 10 April 2018.

Ground pixels affected by sun glint and solar eclipse are removed according to corresponding flags available in the S5P total ozone product (Pedergnana et al., 2018). The remaining LERs from a given day replace the corresponding grid points of the G3_LER map from the previous day. Time information (orbit number) of the LER used in each grid cell is included in the G3_LER maps.

The BRDF dependencies $\rho(\theta)$ are calculated by fitting a polynomial to the TROPOMI LER data normalized to the central detector pixel (nadir viewing) and averaged as a function of the viewing zenith angle. Three different surface types are considered: land, water and snow/ice. Figure 8 shows the BRDF dependencies calculated with normalized
TROPOMI/S5P data from January, April, July, and October 2018. The surface classification is based on the land/water mask and the snow/ice flags from the S5P total ozone product (Pedergnana et al., 2018). Note that these surface types are appropriate for BRDF effects in the UV ozone fitting window; other trace gases retrievals (such as $\mathrm{NO}_{2}$ in the visible spectrum) will require different land cover types (e.g. water, snow/ice, urban, paddy, crop, deciduous forest, and evergreen forest) to properly model BRDF effects; see Noguchi et al. (2014).

Figure 9 shows the TROPOMI/S5P G3_LER daily map for 30 April 2018, plus a comparison with the OMI LER climatology for the month of April. The OMI LER climatol- 

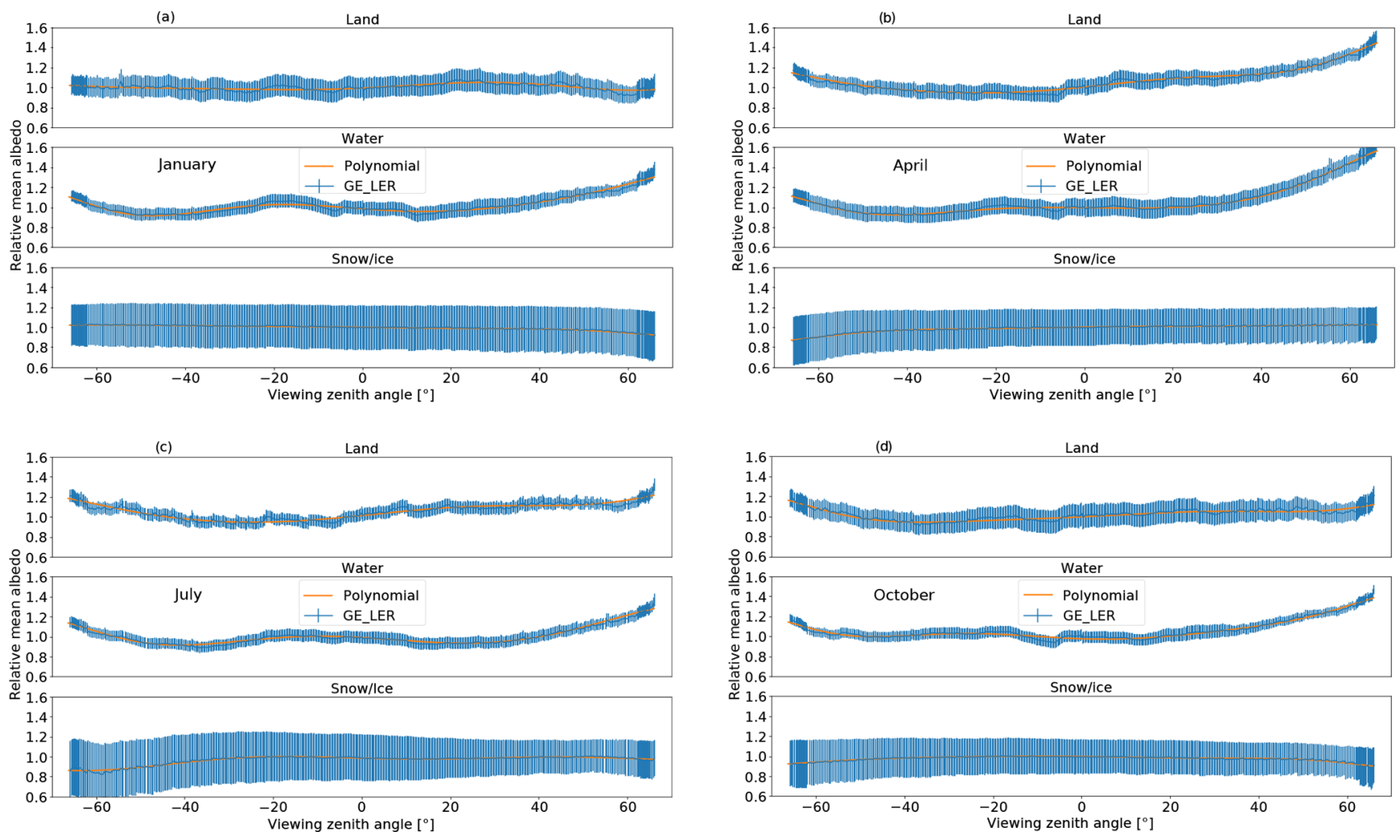

Figure 8. BRDF dependencies $\rho(\theta)$ as a function of the viewing zenith angle for land, water, and snow/ice conditions, as calculated with normalized TROPOMI/S5P data from (a) January, (b) April, (c) July, and (d) October 2018. The negative viewing zenith angles correspond to the first 225 detector pixels

ogy is based on 3 years of data (2004 to 2007) whereas the TROPOMI G3_LER is based on a few weeks of data. The main advantages of the TROPOMI G3_LER daily map compared to climatology are first that it better represents current surface conditions such as snow/ice contamination; second that it accounts for BRDF effects; and third that it has improved spatial resolution $\left(0.1^{\circ}\right)$.

\subsection{G3_LER comparison with OMI and GOME-2 LER}

In this section we compare TROPOMI G3_LER with climatology LER from OMI (Kleipool et al., 2008) and GOME-2 (Tilstra et al., 2017). Since TROPOMI G3_LER is retrieved with a fitting window of 325 to $335 \mathrm{~nm}$, we chose $335 \mathrm{~nm}$ LER values from the two climatologies. For GOME_2 there is no shorter wavelength available in the published dataset, and for the OMI climatology use of the $328 \mathrm{~nm}$ window is not recommended (Kleipool et al., 2010). In the following the instrument names will act as synonym for the respective albedo data sets. The three albedo datasets have different time and horizontal resolutions: OMI covers 4 years with a grid resolution of $0.5^{\circ}$, GOME: covers 6 years with a grid resolution of $0.25^{\circ}$, and TROPOMI covers only 1 year with a grid resolution of $0.1^{\circ}$.
The histograms in Fig. 10 show the differences between the TROPOMI, OMI, and GOME-2 albedo maps for three different surface types: land, water, and snow/ice. A grid cell is assumed to contain snow/ice if the albedo of all three instruments is above 0.7 , and the latitude is outside the $\pm 60^{\circ}$ range. For the snow- and ice-free observations over land and sea, the latitude range was restricted to $\pm 40^{\circ}$. In general the three data sets agree quite well. Over land and water the mean differences are lower than 0.03 and the distributions are small (standard deviation around 0.04). The histograms with S5P over land have tails towards higher values of up to 0.1 , indicating that for some areas S5P data overestimate the albedo. According to the corresponding world maps (Fig. 11) this occurs mainly over rain forests in Brazil, central Africa, or Indonesia, where the TROPOMI data might be affected by residual cloud contamination. Note that for TROPOMI we have only 1 year of data compared to the multiple years for OMI and GOME-2.

Over snow and ice larger deviations are found between OMI and GOME-2 LERs and between TROPOMI G3_LER and the climatological OMI and GOME-2 LERs. The snow/ice information from VIIRS agrees better with the TROPOMI GE_LER albedo than with climatological LERs; see Fig. 12. We conclude that the historical climatologies 
(a) G3 LER

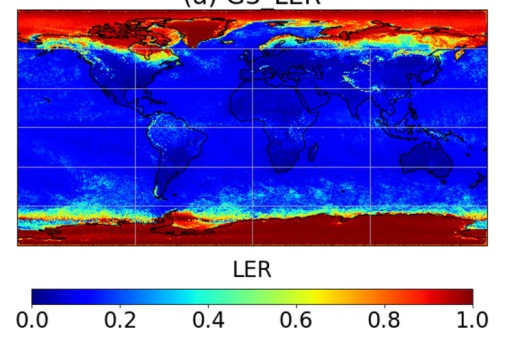

(b) G3 LER minus OMI

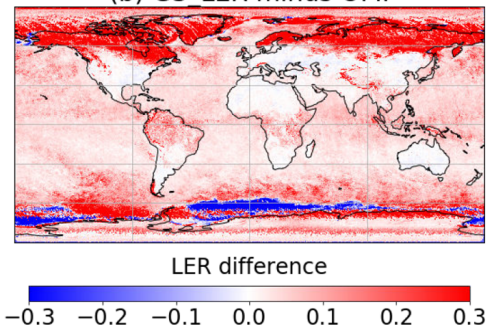

(c) $\mathrm{OMI}$

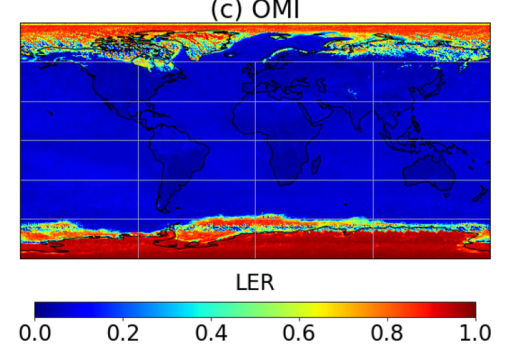

Figure 9. (a) TROPOMI G3_LER daily map (325-335 nm) for 30 April 2018, (c) OMI LER climatology (335 nm) for the month of April, and (b) the difference between these two datasets. There is very good agreement over land and water surfaces, with major differences in snow/ice regions of the OMI LER climatology from 2004 to 2007 that do not match with actual surface conditions observed in April 2018.
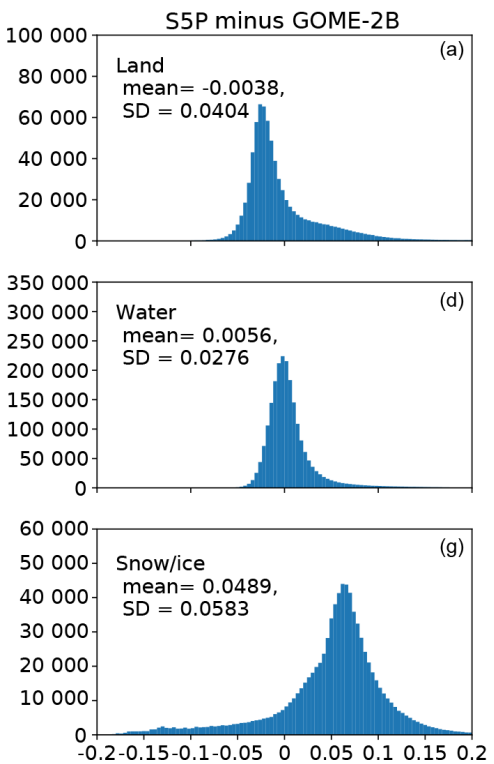
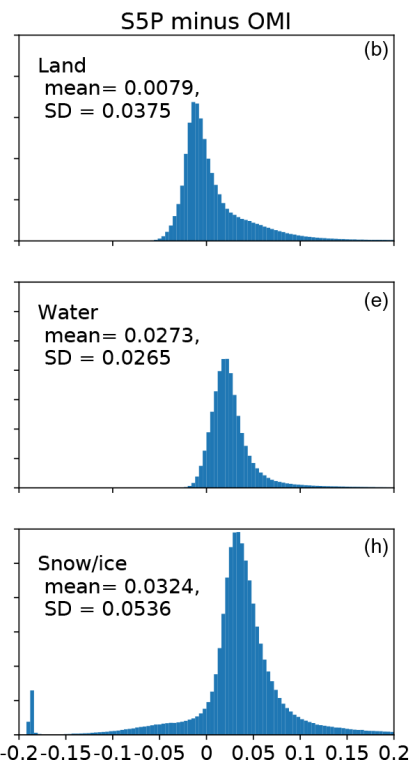
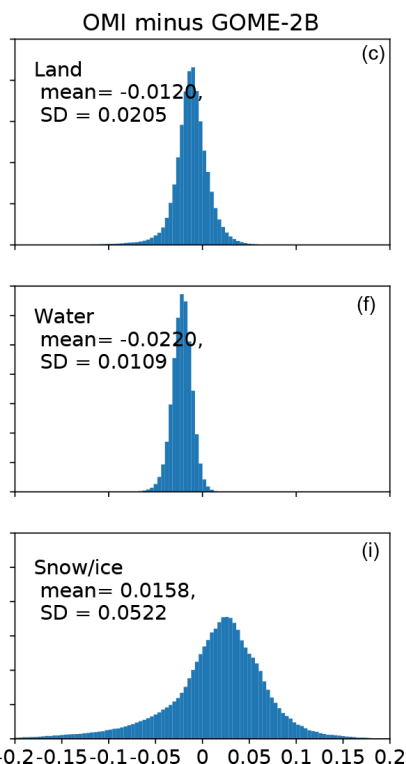

Figure 10. Histograms of the differences (a, d, g) between TROPOMI G3_LER and GOME-2B climatology, (b, e, h) between TROPOMI G3_LER and OMI LER climatology, and $(\mathbf{c}, \mathbf{f}, \mathbf{i})$ between OMI and GOME-2B LER climatologies. The comparisons are performed separately for surface types (land, water, and snow/ice) using data from October 2018.

from OMI and GOME-2 do not properly represent actual snow/ice conditions observed in 2018/2019.

\subsection{Usage of TROPOMI/S5P G3_LER for total ozone retrieval}

The near-real-time S5P total ozone product is based on an iterative DOAS/AMF algorithm (Loyola et al., 2020) and the current operational version (1.1.7) uses the OMI LER climatology (Kleipool et al., 2008). The median bias between near-real-time total ozone from S5P and reference data from Brewer, Dobson, and SAOZ sites is of the order of $+1 \%$ (Verhoelst et al., 2019; Garane et al., 2019).

S5P near-real-time ozone agrees well with the Copernicus Atmosphere Monitoring Service (CAMS) analysis with the exception of some anomalies at high latitudes (Inness et al., 2019). Those anomalies are associated with the coarse resolution of the OMI LER climatology and most importantly, with differences between climatological LER values and the actual surface conditions (mainly snow/ice).

When we replace the OMI LER climatology with the TROPOMI G3_LER daily maps, the resulting total ozone field is significantly smoother and has significantly fewer outliers. Figure 12 shows the TROPOMI/S5P surface albedo and total ozone retrievals from 1 April 2018 around the Bering Strait separating Russia and Alaska. The TROPOMI G3_LER daily map agrees very well with the surface types apparent in the corresponding VIIRS/SNPP images (S5P flies only 3-5 min behind SNPP) including the water surface along the coastline of the Chukchi Sea in Russia and in the north of Alaska as well as along the north coasts of Seward Peninsula in central Alaska. These coastal water surfaces and the open water of the Bering Sea are not well represented in the OMI LER climatology, which indicates snow/ice cover for these sea areas. Similarly, the OMI LER climatology (erroneously) shows no snow/ice cover in the Yukon-Koyukuk 
(a) S5P minus GOME-2B

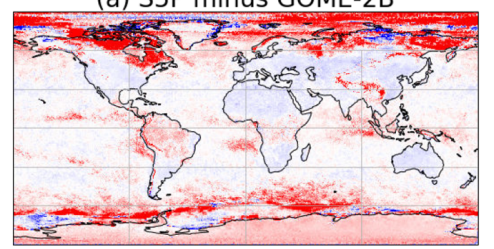

LER difference (b) S5P minus OMI

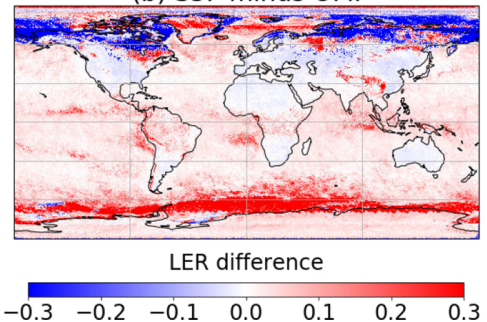

(c) OMI minus GOME-2B

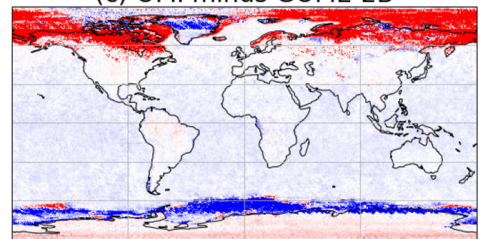

LER difference

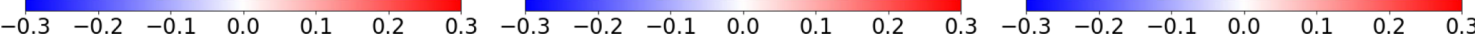

Figure 11. Albedo difference maps between TROPOMI, GOME-2 and OMI for October 2018. North of $60^{\circ} \mathrm{N}$ the discrepancy between the three datasets reaches a maximum due to snow/ice conditions. While S5P overestimates compared to GOME-2, it underestimates compared to OMI.

(a) G3_LER

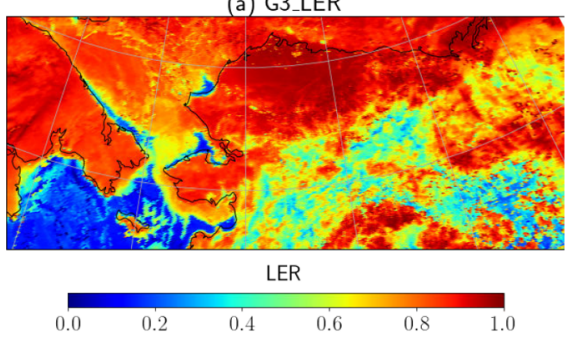

(d) Total ozone column using G3_LER

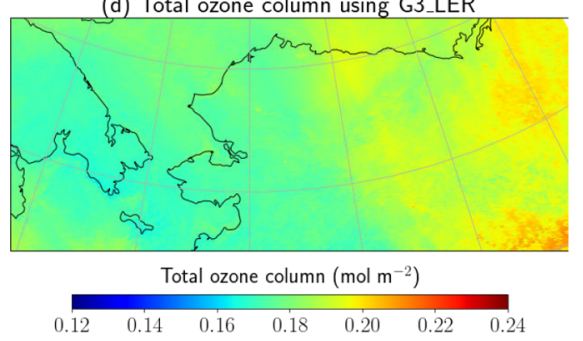

(b) VIIRS/SNPP

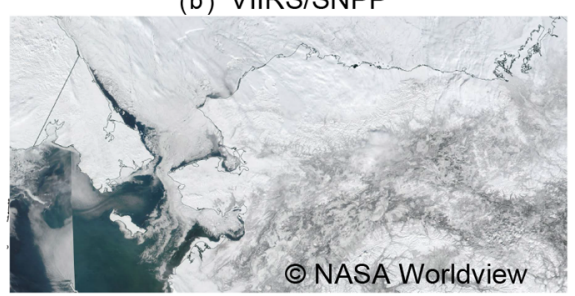

(e) Delta total ozone column

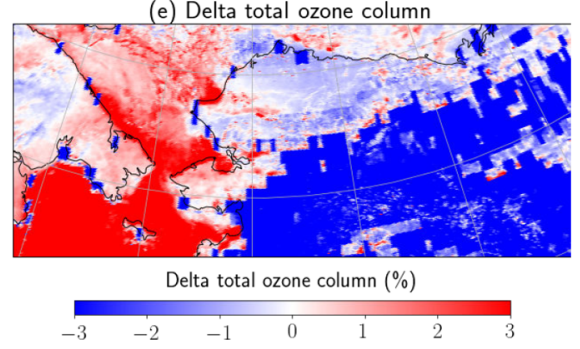

(c) OMI_LER

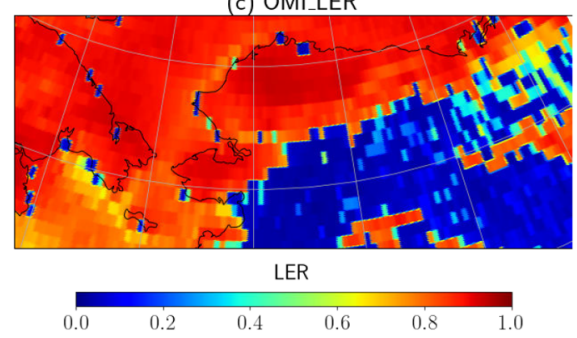

(f) Total ozone column using OMI_LER

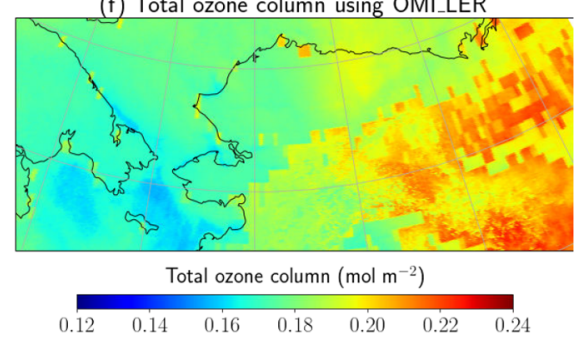

Figure 12. TROPOMI/S5P (a-c) surface and (d-f) ozone measurements from 1 April 2018 around the Bering Strait. The (a) TROPOMI/S5P G3_LER daily map agrees very well with the surface types observed in the (b) VIIRS/SNPP image coastal waters of Russia and Alaska. These coastal waters and the open waters of the Bering Sea are not properly represented in the (c) OMI LER climatology, which shows snow/ice over these regions. Likewise, the OMI LER climatology erroneously shows no snow/ice in Alaska. The total ozone field using the (d) TROPOMI G3_LER daily map is significantly smoother than the field derived from the (f) OMI LER climatology. The coarse spatial resolution of the OMI LER climatology is clearly manifested in the total ozone field and incorrect snow/ice values in the OMI LER climatology induce large errors in the retrieved total ozone (e), with differences between $-10 \%$ and $+15 \%$.

Census Area in Alaska. The coarse spatial resolution of the OMI LER climatology is clearly visible in the total ozone field, and in addition, incorrect snow/ice assignments in the OMI LER climatology induce large errors on the retrieved total ozone, with differences between $-10 \%$ and $+15 \%$.

Moreover, agreement of the S5P total ozone with the CAMS assimilation at high latitudes is significantly better than that for the LER climatologies, as seen in Fig. 13. Mean differences between total ozone from S5P and CAMS for the complete month of April 2018 are summarized in Table 3. The agreement with CAMS improves considerably at all latitudes: the difference in the total ozone for the region 80$60^{\circ} \mathrm{S}$ is reduced from $-2.61 \pm 2.22 \%$ using OMI LER to $0.74 \pm 2.43 \%$ using TROPOMI G3_LER; for $60^{\circ} \mathrm{S}-50^{\circ} \mathrm{N}$, the difference remains at the same level with a small in- crease from $0.23 \pm 1.14 \%$ to $-0.38 \pm 1.13 \%$; in the region $50-70^{\circ} \mathrm{N}$, the difference is reduced from $1.24 \pm 2.45 \%$ to $-0.79 \pm 1.98 \%$; and finally for $70-90^{\circ} \mathrm{N}$ the difference is $-1.001 \pm 2.58 \%$ compared to $-1.35 \pm 2.5 \%$.

\section{Conclusions}

We have developed a novel algorithm for the accurate and fast retrieval of geometry-dependent effective Lambertian equivalent reflectivity (GE_LER) from UVN sensors based on the full-physics inverse learning machine (FP_ILM) technique. The main inputs to the GE_LER retrieval are the DOAS fitting polynomial coefficients and the fitted trace gas slant column amounts, as well as the satellite viewing geometry. The inversion problem is solved using neural networks 

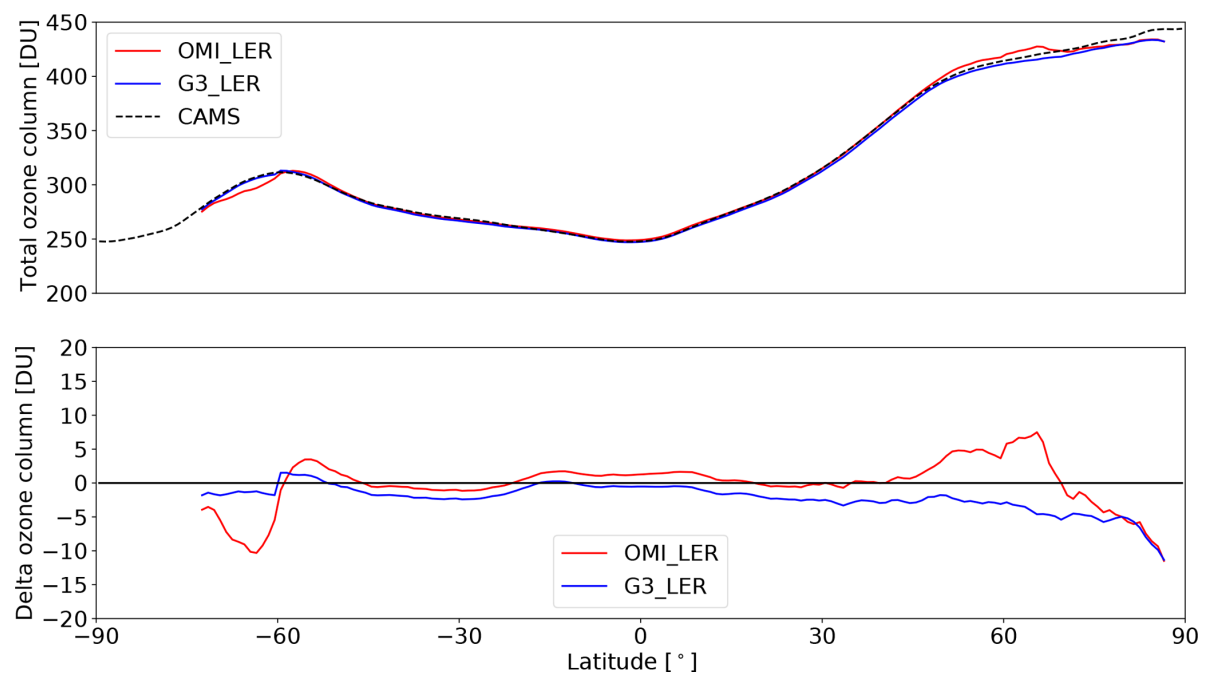

Figure 13. Comparison of total ozone from CAMS and the S5P retrieved ozone using the OMI LER climatology and the daily TROPOMI G3_LER maps for April 2018. Total ozone values based on daily G3_LER maps are significantly closer to those from CAMS especially for high-latitude regions.

Table 3. Latitudinal differences between total ozone from CAMS and S5P using TROPOMI G3_LER and OMI LER for the month of April 2018. The values represent the total number of measurements for each latitudinal range and the mean differences \pm standard deviations (in percentages). Latitude bands with less than 100000 data points were skipped, due to polar winter conditions; there are hardly any data south of $81^{\circ} \mathrm{S}$. The number of measurements increases towards higher north because of overlapping orbits.

\begin{tabular}{lrrr}
\hline Latitude range & Number & TROPOMI G3_LER & OMI LER \\
\hline $80-70^{\circ} \mathrm{S}$ & 11297206 & $-1.341 \pm 2.364$ & $-2.041 \pm 2.114$ \\
$70-60^{\circ} \mathrm{S}$ & 29018428 & $-0.364 \pm 2.472$ & $-2.727 \pm 2.300$ \\
$60-50^{\circ} \mathrm{S}$ & 32351377 & $0.557 \pm 1.783$ & $0.808 \pm 1.815$ \\
$50-40^{\circ} \mathrm{S}$ & 31580917 & $-0.345 \pm 1.189$ & $0.048 \pm 1.224$ \\
$40-30^{\circ} \mathrm{S}$ & 31154717 & $-0.776 \pm 0.906$ & $-0.336 \pm 0.930$ \\
$30-20^{\circ} \mathrm{S}$ & 30948143 & $-0.726 \pm 0.770$ & $-0.252 \pm 0.807$ \\
$20-10^{\circ} \mathrm{S}$ & 30814933 & $-0.001 \pm 0.736$ & $0.537 \pm 0.745$ \\
$10-0^{\circ} \mathrm{S}$ & 30744238 & $-0.163 \pm 0.774$ & $0.517 \pm 0.720$ \\
$0-10^{\circ} \mathrm{N}$ & 30732173 & $-0.199 \pm 0.833$ & $0.607 \pm 0.738$ \\
$10-20^{\circ} \mathrm{N}$ & 30779225 & $-0.581 \pm 0.798$ & $0.142 \pm 0.728$ \\
$20-30^{\circ} \mathrm{N}$ & 30894360 & $-0.788 \pm 0.945$ & $-0.097 \pm 0.901$ \\
$30-40^{\circ} \mathrm{N}$ & 31091907 & $-0.710 \pm 1.340$ & $0.173 \pm 1.336$ \\
$40-50^{\circ} \mathrm{N}$ & 31469922 & $-0.456 \pm 1.858$ & $0.584 \pm 1.880$ \\
$50-60^{\circ} \mathrm{N}$ & 32250750 & $-0.474 \pm 1.721$ & $1.287 \pm 1.920$ \\
$60-70^{\circ} \mathrm{N}$ & 39590441 & $-0.977 \pm 2.211$ & $1.155 \pm 2.798$ \\
$70-80^{\circ} \mathrm{N}$ & 56545121 & $-1.182 \pm 2.581$ & $-0.730 \pm 2.701$ \\
$80-90^{\circ} \mathrm{N}$ & 26178029 & $-1.717 \pm 2.424$ & $-1.595 \pm 2.317$ \\
\hline
\end{tabular}

trained with radiative transfer model simulations based on the same kind of RTM and settings used for the AMF calculations.

A global gapless geometry-dependent LER (G3_LER) daily map can be created from the GE_LER retrievals under clear-sky conditions. The G3_LER daily maps better characterize current surface; in particular they minimize errors induced by the LER climatologies through inaccurate representation of snow/ice scenarios. Both GE_LER and G3_LER account for satellite viewing dependencies, which are characteristic of BRDF effects.

GE_LER is retrieved from each single ground pixel using the same spectrum and DOAS/AMF settings as those employed for trace gas retrievals, and GE_LER is therefore fully consistent with the trace gas retrieval itself. This is in contrast to LER products based on data from other satellites or LER data derived from the same satellite but using a different fitting-window or RTM settings. G3_LER maps are updated on a daily basis using the clear-sky GE_LER for that day, and 
they are evidently superior to LER climatologies, which fail to represent actual surface conditions.

We have applied the FP_ILM algorithm to retrieve GE_LER from TROPOMI for the 325-335 nm fitting window and thereby generate daily G3_LER maps that are used to retrieve the S5P total ozone. S5P total ozone retrievals based on the TROPOMI G3_LER daily maps are clearly superior to those based on OMI_LER climatology. The ozone fields are smoother, but also the difference compared to the total ozone from CAMS in April 2018 is reduced from $-2.53 \pm 2.46 \%$ to $0.78 \pm 3.49 \%$ in the latitudinal region $80-60^{\circ} \mathrm{S}$. Errors in the S5P total ozone between $-10 \%$ and $+15 \%$ induced by snow/ice misrepresentations in the OMI_LER climatology are removed with the FP_ILM GE_LER/G3_LER TROPOMI products.

GE_LER can be applied to any trace gas, cloud, and aerosol product retrieved in the UVN and is fully compatible with the DOAS/AMF settings used for the trace gas retrievals. GE_LER and G3_LER can be used as inputs for computing AMFs, either with the effective scene assumption or the independent pixel approximation. In this paper we demonstrated their effectiveness for improving the quality of TROPOMI total ozone; in the near future we plan to extend GE_LER/G3_LER to fitting windows for the S5P operational UVN cloud product (Loyola et al., 2018), the UV/VIS trace gases $\mathrm{NO}_{2}$ (van Geffen et al., 2018), $\mathrm{SO}_{2}$ (Theys et al., 2017), HCHO (De Smedt et al., 2018), and to fitting windows for S5P research products such as $\mathrm{H}_{2} \mathrm{O}, \mathrm{BrO}, \mathrm{OClO}$, CHOCHO, and aerosol optical depth.

The GE_LER retrieval is accurate and very fast, and is therefore well suited for the (near-real-time) processing of massive amounts of data from the atmospheric Sentinel satellite missions. We plan to apply the FP_ILM GE_LER/G3_LER retrieval to the future Copernicus Sentinel-5 mission that (like Sentinel-5P) tracks along a sun-synchronous polar orbit. Furthermore, we plan to assess the suitability of GE_LER to capture the diurnal LER dependencies on the sun-satellite geometry of the future UVN geostationary missions Sentinel-4, TEMPO, and GMES.

Data availability. TROPOMI/S5P data are freely available from the Copernicus Sentinel-5P data hub: https://s5phub.copernicus.eu (last access: 22 February 2020). The retrieved GE_LER data will be included in the operational TROPOMI/S5P total ozone product version 2.x, foreseen to be available to the public in the third quarter of 2020 .

Author contributions. DGL developed the GE_LER/G3_LER algorithms and prepared the paper with significant contributions from all co-authors. JX performed the RTM simulations and training of the GE_LER retrieval. KPH evaluated/compared the surface and total ozone retrievals and created the corresponding figures. WZ implemented/tested the GE_LER/G3_LER algorithms in the opera- tional Universal Processor for Atmospheric Spectrometers (UPAS) system and processed TROPOMI/S5P data.

Competing interests. The authors declare that they have no conflict of interest.

Acknowledgements. Special thanks to Robert Spurr for longstanding LIDORT support and editorial help. We thank the three reviewers for their insightful comments. This paper contains modified Copernicus Sentinel data processed by DLR. Thanks to EU/ESA/KNMI/DLR for providing the TROPOMI/S5P Level 1 products and NASA Worldview for the VIIRS/SNPP images used in this paper.

Financial support. This study has been supported by DLR (S5P KTR 2472046) for the development of TROPOMI retrieval algorithms.

The article processing charges for this open-access publication were covered by a Research Centre of the Helmholtz Association.

Review statement. This paper was edited by Michel Van Roozendael and reviewed by Christophe Lerot and two anonymous referees.

\section{References}

Ahmad, Z., Bhartia, P. K., and Krotkov, N.: Spectral properties of backscattered UV radiation in cloudy atmospheres, J. Geophys. Res.-Atmos., 109, D01201, https://doi.org/10.1029/2003JD003395, 2004.

Bhartia, P. K., McPeters, R. D., Mateer, C. L., Flynn, L. E., and Wellemeyer, C.: Algorithm for the estimation of vertical ozone profiles from the backscattered ultraviolet technique, J. Geophys. Res., 101, 18793-18806, https://doi.org/10.1029/96JD01165, 1996.

Bodeker, G. E., Hassler, B., Young, P. J., and Portmann, R. W.: A vertically resolved, global, gap-free ozone database for assessing or constraining global climate model simulations, Earth Syst. Sci. Data, 5, 31-43, https://doi.org/10.5194/essd-5-312013, 2013.

Coldewey-Egbers, M., Weber, M., Lamsal, L. N., de Beek, R., Buchwitz, M., and Burrows, J. P.: Total ozone retrieval from GOME UV spectral data using the weighting function DOAS approach, Atmos. Chem. Phys., 5, 1015-1025, https://doi.org/10.5194/acp-5-1015-2005, 2005.

Efremenko, D. S., Loyola R., D. G., Hedelt, P., and Spurr, R. J. D.: Volcanic $\mathrm{SO}_{2}$ plume height retrieval from UV sensors using a full-physics inverse learning machine algorithm, Int. J. Remote Sens., 38, 1-27, https://doi.org/10.1080/01431161.2017.1348644, 2017. 
Garane, K., Koukouli, M.-E., Verhoelst, T., Lerot, C., Heue, K.-P., Fioletov, V., Balis, D., Bais, A., Bazureau, A., Dehn, A., Goutail, F., Granville, J., Griffin, D., Hubert, D., Keppens, A., Lambert, J.-C., Loyola, D., McLinden, C., Pazmino, A., Pommereau, J.-P., Redondas, A., Romahn, F., Valks, P., Van Roozendael, M., Xu, J., Zehner, C., Zerefos, C., and Zimmer, W.: TROPOMI/S5P total ozone column data: global ground-based validation and consistency with other satellite missions, Atmos. Meas. Tech., 12, 5263-5287, https://doi.org/10.5194/amt-12-5263-2019, 2019.

Hedelt, P., Efremenko, D. S., Loyola, D. G., Spurr, R., and Clarisse, L.: Sulfur dioxide layer height retrieval from Sentinel-5 Precursor/TROPOMI using FP_ILM, Atmos. Meas. Tech., 12, 55035517, https://doi.org/10.5194/amt-12-5503-2019, 2019.

Herman, J. R. and Celarier, E. A.: Earth surface reflectivity climatology at 340-380 nm from TOMS data, J. Geophys. Res., 102, 28 003-28 011, https://doi.org/10.1029/97JD02074, 1997.

Inness, A., Flemming, J., Heue, K.-P., Lerot, C., Loyola, D., Ribas, R., Valks, P., van Roozendael, M., Xu, J., and Zimmer, W.: Monitoring and assimilation tests with TROPOMI data in the CAMS system: near-real-time total column ozone, Atmos. Chem. Phys., 19, 3939-3962, https://doi.org/10.5194/acp19-3939-2019, 2019.

Kleipool, Q. L., Dobber, M. R., de Haan, J. F., and Levelt, P. F.: Earth surface reflectance climatology from 3 years of OMI data, J. Geophys. Res., 113, D18308, https://doi.org/10.1029/2008JD010290, 2008.

Kleipool, Q., Ludewig, A., Babić, L., Bartstra, R., Braak, R., Dierssen, W., Dewitte, P.-J., Kenter, P., Landzaat, R., Leloux, J., Loots, E., Meijering, P., van der Plas, E., Rozemeijer, N., Schepers, D., Schiavini, D., Smeets, J., Vacanti, G., Vonk, F., and Veefkind, P.: Pre-launch calibration results of the TROPOMI payload on-board the Sentinel-5 Precursor satellite, Atmos. Meas. Tech., 11, 6439-6479, https://doi.org/10.5194/amt-116439-2018, 2018.

Koelemeijer, R. B. A., de Haan, J. F., and Stammes, P.: A database of spectral surface reflectivity in the range 335-772 nm derived from 5.5 years of GOME observations, J. Geophys. Res., 108, 4070, https://doi.org/10.1029/2002JD002429, 2003.

Labow, G. J., Ziemke, J. R., McPeters, R. D., Haffner, D. P., and Bhartia, P. K.: A total ozone-dependent ozone profile climatology based on ozonesondes and Aura MLS data, J. Geophys. Res.Atmos., 120, 2537-2545, 2015.

Lee, C., Martin R. V., van Donkelaar, A., O’Byrne, G., Richter, A., Huey, G., and Holloway, J. S.: Retrieval of vertical columns of sulfur dioxide from SCIAMACHY and OMI: Air mass factor algorithm development and validation, J. Geophys. Res., 114, D22303, https://doi.org/10.1029/2009JD012123, 2009.

Lerot, C., Van Roozendael, M., Lambert, J.-C., Granville, J., Van Gent, J., Loyola, D., Spurr, R. J. D.: The GODFIT algorithm: a direct fitting approach to improve the accuracy of total ozone measurements from GOME, Int. J. Remote Sens., 31, 543-550, https://doi.org/10.1080/01431160902893576, 2010.

Lerot, C., Van Roozendael, M., Spurr, R., Loyola, D., ColdeweyEgbers, M., Kochenova, S., van Gent, J., Koukouli, M., Balis, D., Lambert, J.-C., Granville, J., and Zehner, C.: Homogenized total ozone data records from the European sensors GOME/ERS2, SCIAMACHY/Envisat, and GOME-2/MetOp-A, J. Geophys. Res., 119, 1639-1662, https://doi.org/10.1002/2013JD020831, 2014.
Lin, J.-T., Martin, R. V., Boersma, K. F., Sneep, M., Stammes, P., Spurr, R., Wang, P., Van Roozendael, M., Clémer, K., and Irie, H.: Retrieving tropospheric nitrogen dioxide from the Ozone Monitoring Instrument: effects of aerosols, surface reflectance anisotropy, and vertical profile of nitrogen dioxide, Atmos. Chem. Phys., 14, 1441-1461, https://doi.org/10.5194/acp14-1441-2014, 2014.

Lorente, A., Boersma, K. F., Stammes, P., Tilstra, L. G., Richter, A., Yu, H., Kharbouche, S., and Muller, J.-P.: The importance of surface reflectance anisotropy for cloud and $\mathrm{NO}_{2}$ retrievals from GOME-2 and OMI, Atmos. Meas. Tech., 11, 4509-4529, https://doi.org/10.5194/amt-11-4509-2018, 2018.

Loyola, D. G.: Applications of Neural Network Methods to the Processing of Earth Observation Satellite Data, Neural Networks, 19, 168-177, https://doi.org/10.1016/j.neunet.2006.01.010, 2006.

Loyola, D. G., Thomas, W., Spurr, R., and Mayer, B.: Global patterns in daytime cloud properties derived from GOME backscatter UV-VIS measurements, Int. J. Remote Sens., 31, 4295-4318, 2010.

Loyola, D. G., Koukouli, M., Valks, P., Balis, D., Hao, N., Van Roozendael, M., Spurr, R., Zimmer, W., Kiemle, S., Lerot, C., and Lambert, J.-C.: The GOME-2 Total Column Ozone Product: Retrieval Algorithm and Ground-Based Validation, J. Geophys. Res., 116, D07302, https://doi.org/10.1029/2010JD014675, 2011.

Loyola, D. G., Pedergnana, M., and Gimeno García, S.: Smart sampling and incremental function learning for very large high dimensional data, Neural Networks, 78, 75-87, https://doi.org/10.1016/j.neunet.2015.09.001, 2016.

Loyola, D. G., Gimeno García, S., Lutz, R., Argyrouli, A., Romahn, F., Spurr, R. J. D., Pedergnana, M., Doicu, A., Molina García, V., and Schüssler, O.: The operational cloud retrieval algorithms from TROPOMI on board Sentinel-5 Precursor, Atmos. Meas. Tech., 11, 409-427, https://doi.org/10.5194/amt-11-4092018, 2018.

Loyola, D. G., Heue, K.-P., Xu, J., Zimmer, W., and Romahn, F.: The near-real-time total ozone retrieval algorithm from TROPOMI onboard Sentinel-5 Precursor, Atmos. Meas. Tech. Discuss., in preparation, 2020.

Lutz, R., Loyola, D., Gimeno García, S., and Romahn, F.: OCRA radiometric cloud fractions for GOME-2 on MetOp-A/B, Atmos. Meas. Tech., 9, 2357-2379, https://doi.org/10.5194/amt-9-23572016, 2016.

Mateer, C. L., Heath, D. F., Krueger, A. J.: Estimation of Total Ozone from Satellite Measurements of Backscattered Ultraviolet Earth Radiance, J. Atmos. Sci., 28, 1307-1311, https://doi.org/10.1175/15200469(1971)028<1307:EOTOFS>2.0.CO;2, 1971.

McPeters, R. D., Frith, S., and Labow, G. J.: OMI total column ozone: extending the long-term data record, Atmos. Meas. Tech., 8, 4845-4850, https://doi.org/10.5194/amt-8-4845-2015, 2015.

Noguchi, K., Richter, A., Rozanov, V., Rozanov, A., Burrows, J. P., Irie, H., and Kita, K.: Effect of surface BRDF of various land cover types on geostationary observations of tropospheric $\mathrm{NO}_{2}$, Atmos. Meas. Tech., 7, 3497-3508, https://doi.org/10.5194/amt7-3497-2014, 2014.

O’Byrne, G., Martin, R. V., van Donkelaar, A., Joiner, J., and Celarier, E. A.: Surface reflectivity from the Ozone Monitor- 
ing Instrument using the Moderate Resolution Imaging Spectroradiometer to eliminate clouds: Effects of snow on ultraviolet and visible trace gas retrievals, J. Geophys. Res., 115, D17305, https://doi.org/10.1029/2009JD013079, 2010.

Pedergnana, M., Loyola, D., Apituley, A., Sneep, M., Veefkind, J. P.: Sentinel-5 precursor/TROPOMI - Level 2 Product User Manual - Ozone Total Column, S5P-L2DLR-PUM-400A, available at: https://sentinel.esa.int/web/ sentinel/technical-guides/sentinel-5p/products-algorithms and http://www.tropomi.eu/documents/pum (last access: 7 February 2020), 2018.

Pflug, B., Aberle, B., Loyola, D., and Valks, P.: Near-Real-Time Estimation of Spectral Surface Albedo from GOME-2/MetOp Measurements, EUMETSAT Meteorological Satellite Conference, Darmstadt, September, 7 pp., 2008.

Qin, W., Fasnacht, Z., Haffner, D., Vasilkov, A., Joiner, J., Krotkov, N., Fisher, B., and Spurr, R.: A geometry-dependent surface Lambertian-equivalent reflectivity product for UV-Vis retrievals - Part 1: Evaluation over land surfaces using measurements from OMI at $466 \mathrm{~nm}$, Atmos. Meas. Tech., 12, 3997-4017, https://doi.org/10.5194/amt-12-3997-2019, 2019.

Rault, D. F. and Taha, G.: Validation of ozone profiles retrieved from Stratospheric Aerosol and Gas Experiment III limb scatter measurements, J. Geophys. Res., 112, D13309, doi:10.1029/2006JD007679, 2007.

Rozemeijer, N. C. and Kleipool, Q.: S5P Level 1b Product Readme File, S5P-MPC-KNMI-PRF-L1B, available at: https://sentinel.esa.int/web/sentinel/technical-guides/ sentinel-5p/products-algorithms and http://www.tropomi. eu/documents/level-0-1b (last access: 7 February 2020), 2019.

Seidel, F. C. and Popp, C.: Critical surface albedo and its implications to aerosol remote sensing, Atmos. Meas. Tech., 5, 16531665, https://doi.org/10.5194/amt-5-1653-2012, 2012.

Siddans, R., S5P-NPP Cloud Processor ATBD, S5P-NPPCRAL-ATBD-0001, available at: https://sentinel.esa.int/web/ sentinel/technical-guides/sentinel-5p/products-algorithms and http://www.tropomi.eu/documents/atbd, (last access: 7 February 2020), 2016.

De Smedt, I., Theys, N., Yu, H., Danckaert, T., Lerot, C., Compernolle, S., Van Roozendael, M., Richter, A., Hilboll, A., Peters, E., Pedergnana, M., Loyola, D., Beirle, S., Wagner, T., Eskes, H., van Geffen, J., Boersma, K. F., and Veefkind, P.: Algorithm theoretical baseline for formaldehyde retrievals from S5P TROPOMI and from the QA4ECV project, Atmos. Meas. Tech., 11, 23952426, https://doi.org/10.5194/amt-11-2395-2018, 2018.

Spurr, R. J. D.: VLIDORT: A linearized pseudo-spherical vector discrete ordinate radiative transfer code for forward model and retrieval studies in multilayer multiple scattering media, J. Quant. Spectrosc. Ra., 102, 316-342, https://doi.org/10.1016/j/jqsrt.2006.05.005, 2006.
Spurr, R., de Haan, J., van Oss, R., and Vasilkov, A.: Discreteordinate radiative transfer in a stratified medium with first-order rotational Raman scattering, J. Quant. Spectrosc. Ra., 109, 404425, 2008.

Theys, N., De Smedt, I., Yu, H., Danckaert, T., van Gent, J., Hörmann, C., Wagner, T., Hedelt, P., Bauer, H., Romahn, F., Pedergnana, M., Loyola, D., and Van Roozendael, M.: Sulfur dioxide retrievals from TROPOMI onboard Sentinel-5 Precursor: algorithm theoretical basis, Atmos. Meas. Tech., 10, 119-153, https://doi.org/10.5194/amt-10-119-2017, 2017.

Tilstra, L. G., Tuinder O. N. E., Wang, P., and Stammes, P.: Surface reflectivity climatologies from UV to NIR determined from Earth observations by GOME-2 and SCIAMACHY, J. Geophys. Res.-Atmos., 122, 4084-4111, https://doi.org/10.1002/2016JD025940, 2017.

van Geffen, J. H. G. M., Eskes, H. J., Boersma, K. F., Maasakkers, J. D., and Veefkind, J. P.: TROPOMI ATBD of the total and tropospheric $\mathrm{NO}_{2}$ data products, S5PKNMI-L2-0005-RP, available at: https://sentinel.esa.int/web/ sentinel/technical-guides/sentinel-5p/products-algorithms and http://www.tropomi.eu/documents/atbd (last access: 7 February 2020), 2018.

Vasilkov, A., Qin, W., Krotkov, N., Lamsal, L., Spurr, R., Haffner, D., Joiner, J., Yang, E.-S., and Marchenko, S.: Accounting for the effects of surface BRDF on satellite cloud and trace-gas retrievals: a new approach based on geometry-dependent Lambertian equivalent reflectivity applied to OMI algorithms, Atmos. Meas. Tech., 10, 333-349, https://doi.org/10.5194/amt-10-3332017, 2017.

Vasilkov, A., Yang, E.-S., Marchenko, S., Qin, W., Lamsal, L., Joiner, J., Krotkov, N., Haffner, D., Bhartia, P. K., and Spurr, R.: A cloud algorithm based on the $\mathrm{O}_{2}-\mathrm{O}_{2} 477 \mathrm{~nm}$ absorption band featuring an advanced spectral fitting method and the use of surface geometry-dependent Lambertian-equivalent reflectivity, Atmos. Meas. Tech., 11, 4093-4107, https://doi.org/10.5194/amt11-4093-2018, 2018.

Verhoelst, T., Granville, J., Lambert, J.-C., and Heue, K.-P.: S5P-MPC-IASB-ROCVR-05.0.1-20191217, available at: http:// mpc-vdaf.tropomi.eu/index.php/ozone (last access: 7 February 2020), 2019.

Xu, J., Schüssler, O., Loyola Rodriguez, D. G., Romahn, F., and Doicu, A.: A novel ozone profile shape retrieval using FullPhysics Inverse Learning Machine (FP_ILM), IEEE J. Sel. Topics Appl. Earth Observ. Remote Sens., 10, 5442-5457, https://doi.org/10.1109/JSTARS.2017.2740168, 2017.

Zhou, Y., Brunner, D., Spurr, R. J. D., Boersma, K. F., Sneep, M., Popp, C., and Buchmann, B.: Accounting for surface reflectance anisotropy in satellite retrievals of tropospheric $\mathrm{NO}_{2}$, Atmos. Meas. Tech., 3, 1185-1203, https://doi.org/10.5194/amt-3-11852010, 2010. 